\title{
The progressive ankylosis gene product ANK regulates extracellular ATP levels in primary articular chondrocytes
}

Ann K Rosenthal ${ }^{1,2^{*}}$, Claudia M Gohr ${ }^{1,2}$, Elizabeth Mitton-Fitzgerald ${ }^{1,2}$, Megan K Lutz ${ }^{1,2}$, George R Dubyak ${ }^{3}$ and Lawrence M Ryan ${ }^{1,2}$

\begin{abstract}
Introduction: Extracellular ATP (eATP) is released by articular chondrocytes under physiological and pathological conditions. High eATP levels cause pathologic calcification, damage cartilage, and mediate pain. We recently showed that stable over-expression of the progressive ankylosis gene product, ANK, increased chondrocyte eATP levels, but the mechanisms of this effect remained unexplored. The purpose of this work was to further investigate mechanisms of eATP efflux in primary articular chondrocytes and to better define the role of ANK in this process.

Methods: We measured eATP levels using a bioluminescence-based assay in adult porcine articular chondrocyte media with or without a 10 minute exposure to hypotonic stress. siRNAs for known ATP membrane transporters and pharmacologic inhibitors of ATP egress pathways were used to identify participants involved in chondrocyte eATP release.
\end{abstract}

Results: eATP levels increased after exposure to hypotonic media in a calcium-dependent manner in monolayer and 3-dimensional agarose gel cultures $(p<0.001)$. A potent transient receptor potential vanilloid 4 (TRPV4) agonist mimicked the effects of hypotonic media. ANK siRNA suppressed basal $(p<0.01)$ and hypotonically-stressed $(p<0.001)$ ATP levels. This effect was not mediated by altered extracellular pyrophosphate (ePPi) levels, and was mimicked by the ANK inhibitor, probenecid $(p<0.001)$. The P2X7/4 receptor inhibitor Brilliant Blue $\mathrm{G}$ also suppressed eATP efflux induced by hypotonic media $(p<0.001)$, while ivermectin, a P2X4 receptor stimulant, increased eATP levels $(p<0.001)$. Pharmacologic inhibitors of hemichannels, maxianion channels and other volume-sensitive eATP efflux pathways did not suppress eATP levels.

Conclusions: These findings implicate ANK and P2X7/4 receptors in chondrocyte eATP efflux. Understanding the mechanisms of eATP efflux may result in novel therapies for calcium crystal arthritis and osteoarthritis.

\section{Introduction}

ATP is a key energy-storing compound found in millimolar concentrations inside healthy cells [1]. Most cell types release ATP to the extracellular space under both physiologic and pathologic conditions [1]. In articular cartilage, low levels of extracellular ATP (eATP) transduce mechanical signals [2]. Higher levels of eATP produce pathologic calcium crystal formation such as that

\footnotetext{
* Correspondence: ann.rosenthal@va.gov

'Rheumatology Section, cc-111 W, Zablocki VA Medical Center, 5000 W. National Ave, Milwaukee, WI 53295-1000, USA

${ }^{2}$ Rheumatology Division, Department of Medicine, Medical College of Wisconsin, Milwaukee, WI, USA

Full list of author information is available at the end of the article
}

seen with calcium pyrophosphate (CPP) and basic calcium phosphate (BCP) crystal deposition in cartilage [3]. eATP also induces production of catabolic mediators such as prostaglandins [4], and activates nociceptive receptors inducing pain [5]. Some of these effects are mediated through purinergic receptors. However, as eATP belongs to the danger-associated molecular pattern (DAMP) family of innate immune signals, it may also contribute to cartilage damage through this mechanism [6,7]. While processes that regulate ATP efflux may be logical therapeutic targets in common degenerative cartilage diseases, surprisingly little is known about transport mechanisms of ATP across the chondrocyte cell membrane.

\section{Biomed Central}

(C) 2013 Rosenthal et al.; licensee BioMed Central Ltd. This is an open access article distributed under the terms of the Creative Commons Attribution License (http://creativecommons.org/licenses/by/2.0), which permits unrestricted use, distribution, and reproduction in any medium, provided the original work is properly cited. 
We recently showed that stable over-expression of the progressive ankylosis gene product (ANK) dramatically increases eATP levels in articular chondrocytes [8]. ANK is a 492 amino acid multipass transmembrane protein originally described as the mutated protein in ank/ank mice [9]. Considerable evidence supports its role in extracellular pyrophosphate $(\mathrm{ePPi})$ transport $[9,10]$. ePPi is a key regulator of pathologic mineralization in cartilage and other tissues. ePPi can be generated from eATP through the action of ecto-enzymes with nucleoside triphosphate pyrophosphohydrolase (NTPPPH) activity, such as ENPP1. Because there is ample ENPP1 activity in normal cartilage to convert all available NTP to NMP and PPi, substrate availability is the rate-limiting step in this reaction [11]. We recently demonstrated that chondrocyte eATP and ePPi elaboration were coordinately regulated [8], supporting a major role for eATP in ePPi production by cartilage. Thus, delineating mechanisms of eATP efflux in cartilage may lead to the identification of novel modulators of ePPi production.

Whether ANK itself may act as an ATP transporter in chondrocytes is not known. Our initial studies involved stable over-expression of ANK, but did not investigate whether over-expression could indirectly increase ATP efflux, for example, by altering the chondrocyte phenotype or affecting levels of eATP metabolizing ecto-enzymes. Structural studies of ANK protein make it unlikely that ANK itself, at least in its monomeric form, is capable of providing a channel of adequate size to accommodate ATP (unpublished observation, C. J. Williams). Thus, the possibility that ANK regulates a known mechanism of cellular ATP export warrants investigation.

Four classic ATP membrane transport mechanisms have been described to date [1]. Hemichannels, composed of either connexin or pannexin proteins, mediate ATP release in many cell types and have been implicated in chondrocyte ATP efflux [12]. Vesicular transport of ATP is best characterized in nerve cells, where ATP is packaged along with other neurotransmitters for rapid release upon cell activation [13]. Vesicular transport of ATP has also been observed in osteoblasts [14]. Two types of molecularly undefined ATP transport channels also exist. Maxianion channels are typically identified by patch clamp experiments, and can be inhibited by anion transport inhibitors and gadolinium [15]. Volume-sensitive outwardly rectifying anion channels (VSOR) or volume-sensitive organic osmolyte and anion channels (VSOAC) are widely expressed channels that rapidly develop after cell swelling. While pharmacologic inhibitors are often used to differentiate between various ATP release mechanisms, interpretations of inhibitor experiments are complicated by considerable overlap in the actions of these agents and anomalous inhibitor responses when multiple transport mechanisms are present in one cell type $[1,16]$.
The ionotropic P2X purinergic receptors, P2X7 and P2X4, have also been implicated in eATP release [17]. These complex receptors respond to stimuli by rapidly opening cation channels and initiating cell signaling. In many cell types, P2X7 and P2X4 receptor channels also comprise or regulate pores capable of transporting molecules as large as $900 \mathrm{Da}$ [18]. P2X7 may co-localize with pannexin proteins, and in some cases hemichannel inhibitors block the activity of the P2X7-regulated large pore $[16,19]$. P2X7 homotrimeric channels can directly interact with P2X4 homotrimeric channels with consequent changes in trafficking and function of these receptors [20]. Whether purine receptors participate in chondrocyte ATP efflux is not fully understood.

ATP release in cartilage is modulated by mechanical stimuli such as tissue compression and by changes in osmotic pressure. These stimuli are linked by similar effects on membrane tension, and often share signaling pathways [21]. Membrane proteins such as the transient receptor potential vanilloid 4 (TRPV4) may participate in the response to these stimuli [22]. Several studies demonstrate increased ATP efflux in chondrocytes subjected to mechanical compression [12,23]. Exposure to osmotic stress is a commonly used model to study ATP efflux [24,25]. Osmotic changes are particularly relevant in cartilage, where mechanical forces repetitively force water in and out of the highly charged extracellular matrix. Normal chondrocytes reside in a hyperosmolar environment (350 to $480 \mathrm{mOsm} / \mathrm{L}$ ), which is reduced in wellestablished osteoarthritis (OA) to 280 to $350 \mathrm{mOsm} / \mathrm{L}$ $[26,27]$. The effects of an osmotic challenge on eATP release in articular chondrocytes and the signals involved in this process remain poorly characterized.

The purpose of this work was to further identify mechanisms of basal and hypotonically stressed eATP efflux in primary articular chondrocytes and characterize the involvement of ANK in these processes.

\section{Methods}

\section{Materials}

Unless otherwise specified, all reagents were from Sigma Aldrich Chemical Co. (St Louis, MO, USA): ${ }^{10}$ panx1 and its scramble control, the P2X7 inhibitors A438079 and AZ10606120, and GSK1016790A, were obtained from Tocris (Ellisville, MO, USA).

\section{Chondrocyte cultures}

Primary hyaline articular chondrocytes were isolated from knee joints of 3- to 5-year-old pigs as previously described [28]. Knee cartilage was obtained from pigs slaughtered at a local abattoir and was used in accordance with guidelines from the Subcommittee on Animal Use of the Research and Development Committee of the Zablocki VA Medical Center. Chondrocytes were plated 
in high-density short-term monolayer cultures and used within 3 days of plating. DMEM (low glucose, $335 \pm 30$ $\mathrm{mOsm} / \mathrm{L}$ ) was used for all experiments. Initial experiments were repeated with chondrocytes embedded in $2 \%$ agarose constructs. To embed chondrocytes, freshly digested cells $\left(5 \times 10^{6}\right.$ cells $\left./ \mathrm{ml}\right)$ were mixed $1: 1$ with $4 \%$ agarose in Hank's Balanced Salt Solution (HBSS). One hundred $\mu \mathrm{l}$ of warm agarose containing cells were added to each well of a 96-well plate and allowed to solidify. After solidification, $150 \mu \mathrm{l}$ of DMEM were added to each well.

\section{eATP measurements}

Media were removed from chondrocytes plated in 96well clear-bottom black plates, and replaced with fresh serum-free DMEM with or without ATP modulators or other additives. After 30 minutes aliquots of media were removed and replaced with an equal volume of sterile water to expose cells to hypotonic media or fresh DMEM as a control. After 10 minutes eATP levels were measured in the media using the Sigma ATP Assay Mix (FLAAM) and read in a BioTek ${ }^{\odot}$ Synergy HT plate reader $\left(\right.$ BioTek $^{\odot}$, Winooski, VT, USA). The osmolarities of all media preparations including those with and without inhibitors and other additives were measured with an Osmette osmometer (Precision Systems, Natick, MA, USA). Media osmolarities were as follows: undiluted media 362 to 302 $\mathrm{mOsm} / \mathrm{L}, 15 \% \mathrm{H}_{2} \mathrm{O} 282$ to $249 \mathrm{mOsm} / \mathrm{L}, 35 \% \mathrm{H}_{2} \mathrm{O} 216$ to $192 \mathrm{mOsm} / \mathrm{L}$, and 50\% $\mathrm{H} 2 \mathrm{O} 166$ to $143 \mathrm{mOsm} / \mathrm{L}$. No media additives, except for water, altered media osmolarity more than $10 \%$ (data not shown). We chose to use 10 to $50 \%$ water as an osmotic challenge, as this level of osmotic stress typically induces eATP release in other cell types $[29,30]$. Each culture additive and osmotic condition was tested for effects on the ATP standard curve. If effects were noted, as they were in the case of sodium pyrophosphate (NaPPi) and Brilliant Blue G (BBG), calculated ATP levels were adjusted accordingly.

\section{ATP metabolizing ecto-enzyme activities}

Specific activities of the ecto-enzymes that metabolize ATP were measured, as changes in these enzyme activities could affect eATP levels without altering transport. NTPPPH activity was measured using $2 \mathrm{mM}$ p-nitrophenol thymidine monophosphate (PNPMP) as a substrate. Briefly, the media were removed and replaced with PNPMP in HBSS. The cells were incubated for $2 \mathrm{~h}$ at $37^{\circ} \mathrm{C}$ and the reaction was stopped with the addition of $0.1 \mathrm{~N} \mathrm{NaOH}$. The absorbance was measured at $410 \mathrm{~nm}$ using a Biotek plate reader. Activity of the phosphate-generating enzyme, $5^{\prime}$ nucleotidase $\left(5^{\prime} \mathrm{NT}\right)$, was determined with a kit used according to manufacturer's directions (BQ Kits, San Diego, CA, USA) [31]. Alkaline phosphatase activity was measured using p-nitrophenol phosphate (PNPP) as a chromogenic substrate. Cells were lysed in $0.9 \%$ saline with $0.2 \%$ Triton $^{\text {тм }}$ $\mathrm{x}-100$. Equal volumes of alkaline buffer solution and PNPP were added and incubated for 15 minutes at $37^{\circ} \mathrm{C}$. The reaction was stopped with $0.05 \mathrm{~N} \mathrm{NaOH}$ and absorbance was measured as described above. All results were corrected for protein levels in the samples using the Lowry assay.

\section{Calcium dependence}

To determine if the ATP response to a hypotonic challenge was calcium dependent, we exposed chondrocytes to the calcium ionophore, A23187. Bis-N,N,N',N'-tetraacetic acid-AM (BAPTA-AM) was used to buffer changes in intracellular calcium flux as described [32,33]. We also explored the ability of the TRPV4 agonist GSK1016790A to stimulate eATP efflux.

\section{Cell toxicity}

All culture additives were tested for toxicity using the 3(4,5-dimethylthiazol-2-yl)-2,5-diphenyltetrazolium bromide (MTT) formazan assay according to manufacturer's directions.

\section{Chondrocyte transfection}

Chondrocytes freshly isolated from whole cartilage were nucleofected with siRNA for the protein of interest or non-targeting scramble control with an Amaxa Nucleofection device using program H-020. All silencers were purchased from Life Technologies (Grand Island, NY, USA). Stealth silencers for P2X4 and P2X7 were custom designed using porcine-specific sequences, and ANK silencer (133667) was predesigned and prevalidated. Prior to plating transfected cells, viability was assessed with trypan blue. Transfected chondrocytes were incubated in monolayer cultures for 48 to $72 \mathrm{~h}$ prior to RNA isolation, and eATP measurements were performed.

\section{RNA isolation, reverse transcription and real-time PCR}

Total RNA was extracted from chondrocytes using the PureLink Mini RNA kit (Life Technologies). cDNA was synthesized from $1 \mu \mathrm{g}$ of total RNA using QuantiTect Reverse Transcription kit (Qiagen, Valencia, CA, USA), which includes a genomic DNA elimination step. mRNA expression was measured by quantitative real-time PCR using SYBR Green Master I Mix on the LightCycler 480 Real-Time PCR System (Roche, Indianapolis, IN, USA). Two reference genes were selected for normalization after determining they were stably expressed across samples. After verifying similar amplification efficiencies with a 5point standard curve, the comparative cycle threshold $(\mathrm{Ct})$ method was used to calculate fold change. Cycling conditions were set as follows: one cycle at $95^{\circ} \mathrm{C}$ for 10 minutes, 40 cycles of $95^{\circ} \mathrm{C}$ for 15 seconds, $60^{\circ} \mathrm{C}$ for 30 seconds, and $72^{\circ} \mathrm{C}$ for 15 seconds. A melting curve analysis was performed to confirm amplification specificity. The final PCR 
products were electrophoresed on a $1 \%$ ethidium bromidestained agarose gel to verify the presence of a single band. Primer sequences are available upon request.

\section{Western blotting}

Chondrocyte lysates were loaded onto $10 \%$ NuPage ${ }^{\odot}$ (Invitrogen, Grand Island, NY, USA) Bis-Tris gels. After electrophoresis, proteins were blotted onto poly-(vinylidene) difluoride membranes (Life Technologies). Membranes were blocked in a Tris-buffered saline (TBS)-igepal$5 \%$ skim milk buffer for $1 \mathrm{~h}$ at room temperature. They were then exposed to antibodies directed against connexin-43 (Abcam, Cambridge, MA, USA), pannexin 1 and 3, ANK, P2X4, P2X7 and TRPV4 (Santa Cruz, Santa Cruz, CA, USA) at $1: 1,000$ to 10,000 dilution for 1.5 to $24.0 \mathrm{~h}$. After washing, the membranes were exposed to peroxidase-labeled goat anti-rabbit $\operatorname{IgG}(\mathrm{H}+\mathrm{L})$ or rabbit anti-goat for $1 \mathrm{~h}(1: 2,500)$ (Life Technologies). Both the primary and secondary antibody exposures were performed in a TBS-igepal-0.5\% skim milk buffer. SuperSignal ${ }^{\odot}$ West Femto Maximum Sensitivity Substrate (Pierce, Rockford, IL, USA) was used to visualize immunoreactive protein bands.

\section{Prostaglandin $\mathrm{E}_{2}$ levels}

Prostaglandin $\mathrm{E}_{2}$ levels in chondrocyte media were measured using Parameter ${ }^{\mathrm{TM}}$ Prostaglandin $\mathrm{E}_{2}$ kit (R\&D Systems, Minneapolis, MN, USA) according to manufacturer's directions.

\section{Statistics}

All experiments were repeated a minimum of three times. An individual experiment is considered as the data derived from a chondrocyte culture isolated from one set of pig knees. The number of replicates (n) within experiments was typically eight in each group. As ATP levels failed to satisfy criteria for parametric variables, the non-parametric Mann-Whitney $U$-test was used to determine the statistical significance of the inhibitor effects on eATP release. Parametric outcomes were evaluated with the unpaired Student $t$-test. Statistical significance was set at $P<0.05$.

\section{Results}

eATP levels in chondrocyte media are increased by exposure to hypotonic conditions, and proteins implicated in eATP efflux are present in chondrocytes

Baseline eATP levels in chondrocyte-conditioned media were consistently measureable, but absolute values varied considerably between experiments. Exposure to more than $35 \%$ water significantly increased eATP levels after 10 minutes in a dose-dependent manner as shown in the representative experiment in Figure $1 \mathrm{~A}(P<0.001)$. We demonstrated an identical dose response to a hypotonic challenge in chondrocytes embedded in an agarose matrix $(P<0.001)$ (Figure $1 \mathrm{~B})$. Levels fell back to baseline levels $2 \mathrm{~h}$ after a hypotonic challenge (Figure $1 \mathrm{C}$ ). These findings support the physiologic relevance of the monolayer culture system. For all further experiments, monolayer cultures were utilized, and exposure to 35\% water for 10 minutes was chosen as the standard hypotonic challenge. To characterize the potential participants in eATP efflux in primary chondrocytes, we ensured that pannexin-1 and -3 , connexin 43, ANK, P2X7, and P2X4 were present using western blotting and reverse transcription (RT)-PCR (Figure 1D).

The response to a hypotonic challenge is calcium-dependent and mimicked by a specific TRPV4 agonist

As shown in Figure 2A, the calcium ionophore A23187 stimulated eATP efflux and mimicked the effects of exposure to hypotonic media $(P<0.001)$. As calcium ionophores have additional cellular effects, we also investigated the actions of BAPTA-AM, which buffers intracellular calcium. BAPTA-AM reduced the effect of the hypotonic challenge on eATP efflux $(P<0.001)$, supporting a role for calcium (Figure 2B). BAPTA-AM had no effect on basal levels of eATP. TRPV4 is an osmotically-sensitive non-selective cation channel that has been implicated in ATP efflux in other cell types [34] and is present in chondrocytes (Figure 2D). Figure 2C shows that the TRPV4 agonist, GSK1016790A, mimics the effects of a hypotonic challenge $(P<0.001)$. A role for TRPV4 in mediating the effects of hypotonicity is further supported by the lack of response to a hypertonic challenge (Figure 2E), a property characteristic of TRPV4-mediated effects [22].

\section{ANK siRNA suppressed basal and hypotonically stressed eATP levels in chondrocyte cultures}

We have previously shown that over-expression of the putative ePPi transporter ANK in chondrocytes resulted in a 10-fold increase in eATP levels compared to controls transfected with an empty viral vector [8]. To extend these findings, we explored the effect of specifically reducing ANK levels on eATP levels in chondrocyte media. eATP levels were suppressed in chondrocytes treated with ANK siRNA compared to those treated with a scramble control $(P<0.001)$ (Figure $3 \mathrm{~A})$, without alterations of ecto-enzyme activities or cell viability (data not shown). ANK mRNA $(P<0.01)$ (Figure $3 \mathrm{~B})$ and protein levels (Figure $3 \mathrm{C}$ ) were significantly reduced in ANK siRNA-treated chondrocytes. To ensure that reductions in eATP in ANK-silenced cells were not indirectly due to decreases in ePPi levels, we added back 10 to $100 \mu \mathrm{M}$ $\mathrm{NaPPi}$ to the media of ANK-silenced cells and measured eATP levels. NaPPi did not alter the $\mathrm{pH}$ of the media, which remained at $\mathrm{pH}$ 7.4. As shown in the representative experiment in Figure 3D, the presence of exogenous 


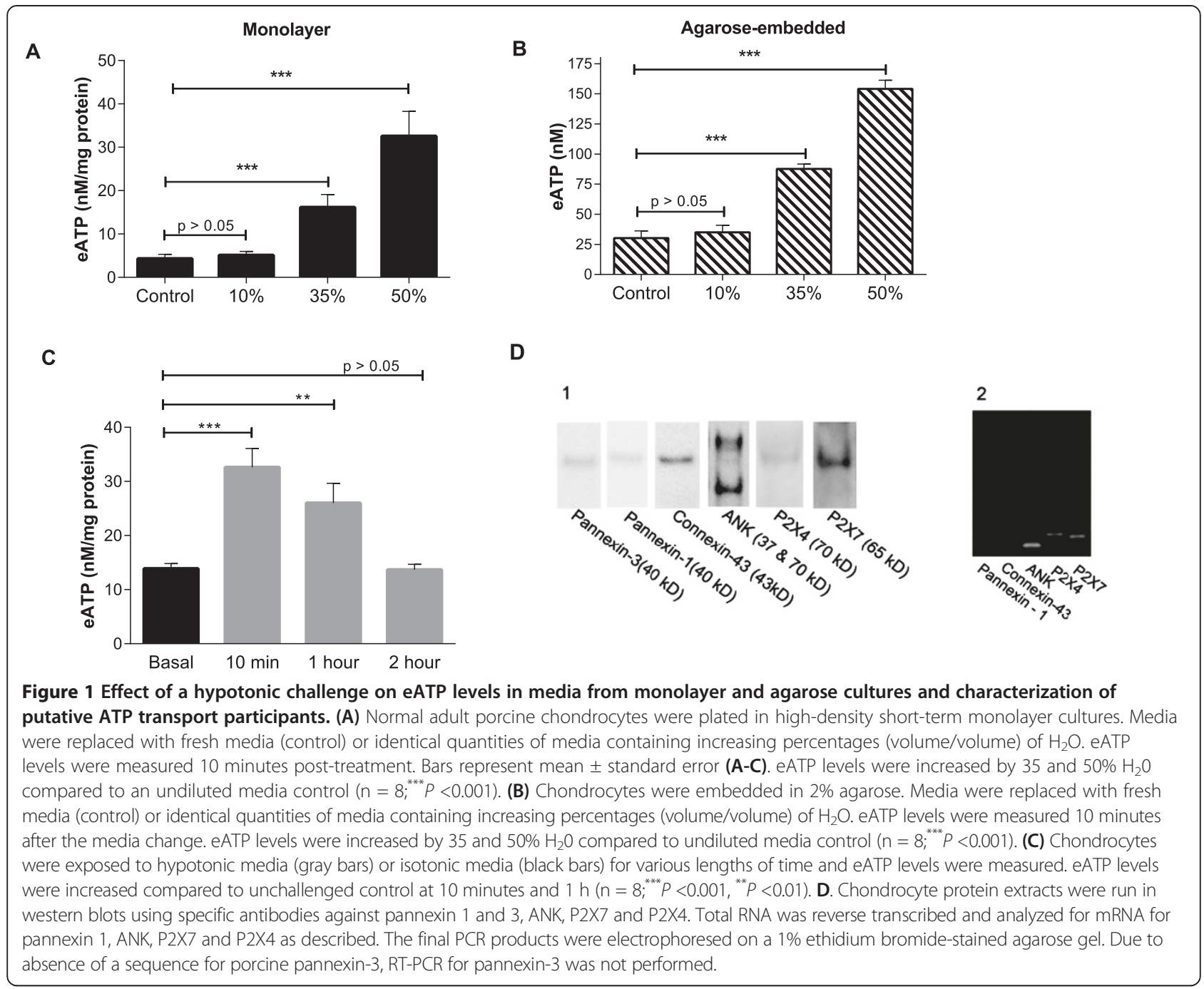

PPi did not restore eATP levels in ANK-silenced cells towards levels seen in the scramble control. However, there were small increases in eATP levels in the presence of added ePPi seen across groups, which were not statistically significant. These data suggest that the reduction in eATP seen with ANK silencing is not mediated by changes in ePPi concentrations. Probenecid, which has been shown to inhibit ANK-mediated PPi transport [35], reduced eATP levels in a dose-dependent manner $(P<0.001)$ (Figure 3E).

\section{ANK may act to directly transport ATP or regulate other ATP transport mechanisms}

We also designed experiments to test for the presence of classic ATP egress pathways by investigating the effects of inhibitors of these pathways. None of the pharmacologic inhibitors reduced basal eATP levels with the exception of probenecid (data not shown). Table 1 summarizes the effects of these pharmacologic inhibitors on eATP levels measured after a hypotonic challenge. Results are expressed as the fold change in eATP levels after a hypotonic challenge in the presence of the inhibitor compared to the absence of the inhibitor. Despite the expression of hemichannels, including pannexin- 1 and connexin- 43 , by chondrocytes at the protein and mRNA levels (Figure 1D), multiple pharmacological inhibitors known to target hemichannels failed to suppress osmotically induced chondrocyte ATP. The effect of ${ }^{10}$ panx1, a small peptide inhibitor of pannexin-1 hemichannels [36], was indistinguishable from its control peptide at concentrations from 100 to $400 \mu \mathrm{M}$. Flufenamic acid (30 to $500 \mu \mathrm{M})$ and carbenoxolone (1 to $100 \mu \mathrm{M})$ also failed to significantly suppress hypotonically-induced eATP production. Small decreases in eATP levels were seen with vesicular transport inhibitors, including monensin $(100 \mu \mathrm{M})$ and brefeldin $(100 \mu \mathrm{M})$, but these failed to achieve statistical significance. Inhibitors implicated in the molecularly undefined maxianion and VSOARC 

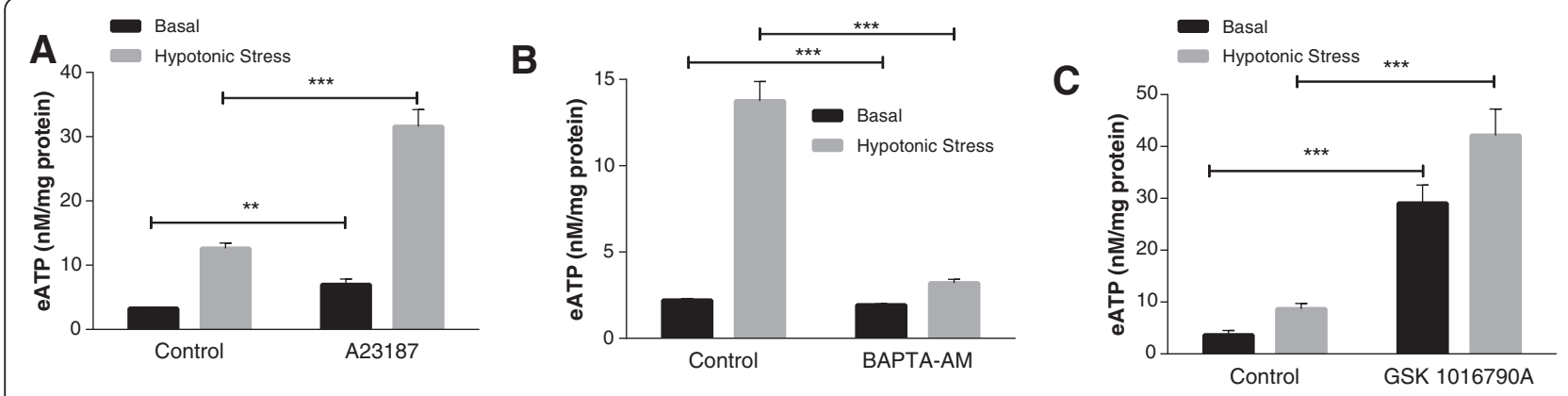

D

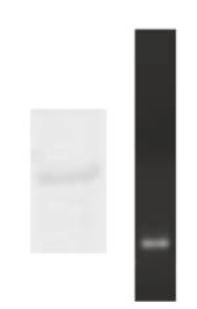

\section{$E$}

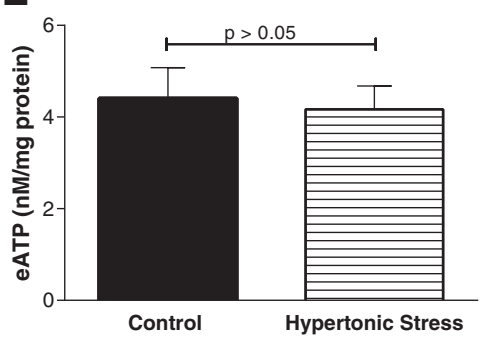

Figure 2 Roles of $\mathrm{Ca}^{2+}$ signaling and transient receptor potential vanilloid 4 (TRPV4) channels in hypotonically-induced release of eATP from chondrocytes. For the following experiments, chondrocytes were incubated with each additive for 30 minutes in $100 \mu$ l of media with no additives acting as a control. A hypotonic challenge was initiated by removing $35 \mu$ l of media, replacing it with $35 \mu l$ of $\mathrm{H}_{2} \mathrm{O}$. eATP levels were measured after 10 minutes. Bars represent mean \pm standard error. Under control conditions, a hypotonic challenge consistently increases (eATP). (A) Chondrocytes were incubated with $100 \mu \mathrm{M}$ A23187, which increased eATP levels $\left(n=8 ;{ }^{* *} P<0.01,{ }^{* * *} P<0.001\right)$. (B) Chondrocytes were incubated with $10 \mu \mathrm{M}$ bis-N,N,N',N'-tetraacetic acid-AM (BAPTA-AM), which decreased eATP levels after hypotonic challenge compared to control without BAPTA-AM ( $\left.n=8 ;{ }^{* * *} P<0.001\right)$. (C) Chondrocytes were incubated with $100 \mathrm{nM}$ GSK1016790A, which increased eATP levels in the basal state and after a hypotonic challenge compared to a control without GSK 1016790 ( $\left.n=8 ;{ }^{* * *} P<0.001\right)$. (D) Chondrocyte protein extracts were run in western blots with TRPV4 antibody (leftpanel). mRNA for TRPV4 was detected with RT-PCR using a specific primer sequence and electrophoresed on a 1\% ethidium bromide-stained agarose gel ( right panel). (E) Chondrocytes were incubated with control media (black bars) or media containing an additional $100 \mathrm{mM} \mathrm{NaCl}$ (gray bars) for 10 minutes after which eATP levels were measured. A hypertonic challenge did not increase eATP levels compared to the basal state $(n=8 ; P>0.05)$.

channels such as gadolinium $(50 \mu \mathrm{M})$ did not effectively decrease eATP levels in the media from osmotically stressed chondrocytes.

\section{Possible roles for $\mathrm{P} 2 \mathrm{X} 7$ and $\mathrm{P} 2 \mathrm{X} 4$ receptor channels in chondrocyte eATP release}

The insensitivity of chondrocyte eATP accumulation to multiple inhibitors that target defined ATP release mechanisms was surprising. Although many studies with these inhibitors have been performed in cells that overexpress proteins involved in a single ATP transport mechanism pathway, ATP transport mechanisms have been successfully teased out in primary cells using these methodologies [14]. P2X7 receptors may play a direct role in eATP release in some cell types, as the large pore that opens upon P2X7 activation may itself release ATP [17]. P2X4 may also function in this manner [37]. P2X7 and $\mathrm{P} 2 \mathrm{X} 4$ receptor protein and mRNA are expressed in primary chondrocytes (Figure 1D). Complexes containing both P2X7 homotrimeric channels and P2X4 homotrimeric channels have been characterized in leukocytes $[20,38]$. As shown in Table 1, we explored the effects of three different P2X7 receptor inhibitors on eATP release.
BBG, which inhibits both P2X4 and P2X7 receptors, significantly suppressed eATP levels after a hypotonic challenge, whereas two specific P2X7 receptor inhibitors, A438079 and AZ10606120, failed to do so. No effects on basal eATP levels were seen with any of these inhibitors (data not shown). To determine whether this pattern correlated with other putative $\mathrm{P} 2 \mathrm{X} 7$ receptor-mediated actions, we measured ATP-induced prostaglandin $\mathrm{E}_{2}\left(\mathrm{PGE}_{2}\right)$ release from chondrocytes, which is a P2X receptordependent effect, and may also be associated with pore formation [39]. Only BBG inhibited $\mathrm{PGE}_{2}$ release by chondrocytes $(P<0.001)$ (Figure 4A). Moreover, treatment of chondrocytes with siRNA that targeted P2X7 receptors failed to significantly decrease hypotonically-stressed ATP release (Figure 4B) despite causing decreased levels of P2X7 receptor protein (Figure $4 C)$ and mRNA $(P<0.05)$ (Figure 4D). The ability of BBG but not A438079, AZ10606120, or P2X7 siRNA to attenuate ATP release suggested involvement of the P2X4 subtype. Among the P2X receptors, P2X4 receptors characteristically respond to ivermectin with increased channel gating and activity. As shown in Figure 5A, ivermectin increased eATP levels in chondrocytes after a hypotonic challenge $(P<0.001)$. 


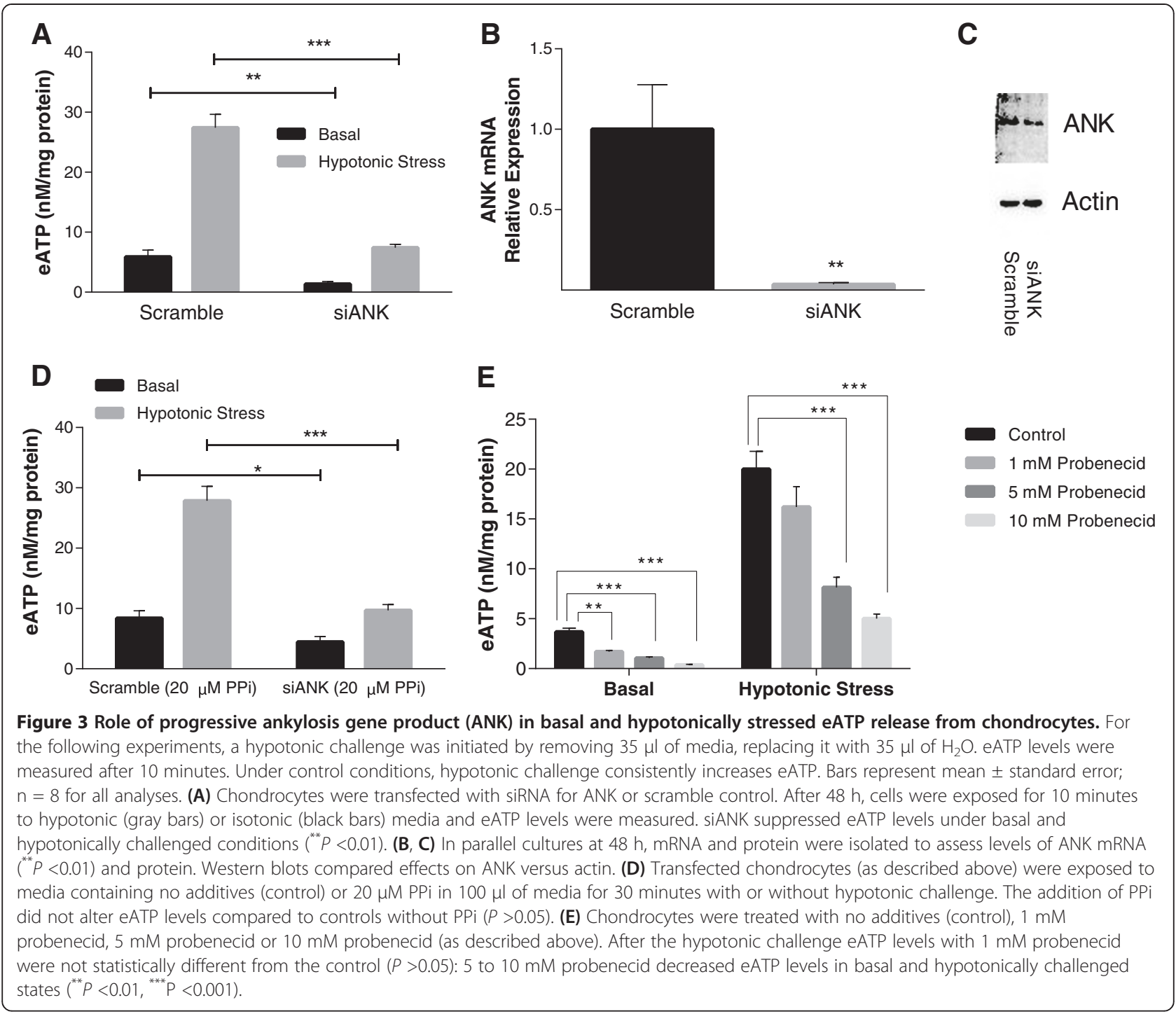

Although we were able to effectively decrease levels of P2X4 protein (Figure $5 \mathrm{C})$ and mRNA $(P<0.01)$ (Figure 5D) in chondrocytes treated with P2X4-siRNA, no differences were observed in eATP levels in P2X4 silenced cells compared to control cells (Figure 5B). Taken together, these data suggest a redundant system, in which both P2X4 and P2X7 must be inhibited for ATP efflux to be affected.

\section{Pharmacological inhibitors of ATP efflux do not alter ATP-metabolizing ecto-enzyme activity levels or decrease cell viability}

eATP levels can be altered by changes in the activities of the ecto-enzymes that metabolize ATP. Cell damage may also non-specifically increase eATP levels by allowing leakage from injured cells. To verify that these possible effects did not contribute to the action of the pharmacological inhibitors on eATP, we measured activities of ecto-
NTPPPH, $5^{\prime} \mathrm{NT}$ and alkaline phosphatase in the presence and absence of inhibitors, and used the MTT assay as a standard measure of cell injury. None of the inhibitors significantly altered levels of enzyme activities (Table 1). With the exception of flufenamic acid, which was toxic at concentrations greater than $100 \mu \mathrm{M}$, no inhibitors or inhibitor combinations significantly decreased cell viability.

\section{Discussion}

These findings support a major and novel role for ANK in eATP efflux in articular chondrocytes. While it is unclear whether ANK itself acts as an ATP channel or regulates such a channel, we propose that the latter possibility is more likely based on our additional findings that suggest roles for P2X7/4 receptors in this process. eATP promotes many of the pathogenic processes resulting in calcium crystal deposition and OA in cartilage. Thus, 
Table 1 Effects of pharmacologic ATP transport inhibitors on eATP levels, ATP-metabolizing ecto-enzyme activities, and cell toxicity in hypotonically stressed chondrocyte cultures

\begin{tabular}{|c|c|c|c|c|c|c|c|c|c|}
\hline Inhibitor & Target & Dosage & Fold change in ATP & $P$ & $\mathrm{~N}$ & Alk phos & NTPPPH & $5^{\prime} \mathrm{NT}$ & Toxicity (fold change) \\
\hline Probenecid & ANK, Hemichannels & $5 \mathrm{mM}$ & $0.59^{*}$ & 0.004 & 83 & $103 \pm 2.9$ & $108 \pm 6.9$ & $122 \pm 24.8$ & 1.31 \\
\hline Monensin & Vesicular & $100 \mathrm{uM}$ & 0.74 & 0.097 & 50 & $103 \pm 1.8$ & $109 \pm 5.3$ & $120 \pm 20.2$ & 1.49 \\
\hline $\mathrm{GdCl}_{3}$ & Maxianion & $50 \mathrm{uM}$ & 0.88 & 0.309 & 51 & $106 \pm 6.9$ & $104 \pm 2.1$ & $126 \pm 11.9$ & 2.21 \\
\hline N-ethylmalemide (NEM) & Vesicular & 100 uM & 0.89 & 0.947 & 57 & $101 \pm 3.2$ & $110 \pm 3.6$ & $116 \pm 19.3$ & 1.68 \\
\hline Brefeldin & Vesicular & 100 uM & 0.88 & 0.739 & 60 & $101 \pm 3.2$ & $110 \pm 3.6$ & $116 \pm 19.3$ & 1.68 \\
\hline Carbeneoxolone (CBX) & Hemichannels & $5 \mathrm{uM}$ & 1.45 & 0.627 & 40 & $103 \pm 2.9$ & $109 \pm 8.4$ & $109 \pm 16.9$ & 3.25 \\
\hline Flufenamic acid (FFA) & Hemichannels & $30 \mathrm{uM}$ & 1.14 & 0.545 & 40 & $98 \pm 6.5$ & $118 \pm 6.0$ & $108 \pm 14.4$ & 1.33 \\
\hline${ }^{10} \mathrm{Pan} \times 1$ & Pannexin-1 & $100 \mathrm{uM}$ & 1.3 & 0.850 & 43 & $105 \pm 4.7$ & $137 \pm 4.6$ & $115 \pm 16.8$ & 1.33 \\
\hline${ }^{10}$ Panx1 Scramble & Pannexin-1 & 100 uM & 1.5 & 0.256 & 41 & $104 \pm 6.6$ & $142 \pm 8.8$ & $83 \pm 10.8$ & 1.27 \\
\hline Brilliant Blue G & $\mathrm{P} 2 \mathrm{X} 7, \mathrm{P} 2 \mathrm{X} 4$ & $50 \mathrm{uM}$ & $0.367^{*}$ & 0.001 & 24 & $147 \pm 5.9$ & $142 \pm 7.4$ & $155 \pm 32$ & 1.26 \\
\hline A438079 & $\mathrm{P} 2 \mathrm{X7}$ & $300 \mathrm{~nm}$ & 2 & 0.042 & 24 & $131 \pm 4.4$ & $136 \pm 5.7$ & $92 \pm 21.9$ & 1.25 \\
\hline AZ10606120 & $\mathrm{P} 2 \mathrm{X7}$ & $10 \mathrm{nM}$ & 1.2 & 0.806 & 24 & $123 \pm 6.9$ & $124 \pm 4.6$ & $104 \pm 23.6$ & 1.12 \\
\hline
\end{tabular}

Chondrocytes were exposed to control media with and without various pharmacologic ATP pathway inhibitors for 30 minutes. Aliquots of media were removed and replaced with $35 \% \mathrm{H}_{2} 0$ as described. After 10 minutes, eATP levels were measured in the media. eATP results are expressed as a mean fold change in osmotically challenged eATP levels over control (no inhibitor) conditions; $\mathrm{N}=$ number of replicates pooled from three to five experiments: * ${ }^{*}$ tatistically significantly inhibition of ATP levels compared to controls. In parallel cultures, specific activities of ATP metabolizing enzymes - alkaline phosphatase (Alk phos), nucleoside triphosphate pyrophosphohydrolase (NTPPPH), and 5' nucleotidase (5' NT) - were measured in the cell layer using standard colorimetric assays. Results are expressed as percent of specific activity of the control (no inhibitor) conditions (means \pm standard error, $n=6$ ). Cell toxicity was measured with the 3-(4,5-dimethylthiazol-2-yl)-2,5-diphenyltetrazolium bromide (MTT) assay. Results are expressed as a fold increase over control (no inhibitor) conditions. There were no statistically significant changes in levels of Alk phos, NTPPPH, 5'NT activity or cell toxicity in the presence of inhibitors. ANK, progressive ankylosis gene product.
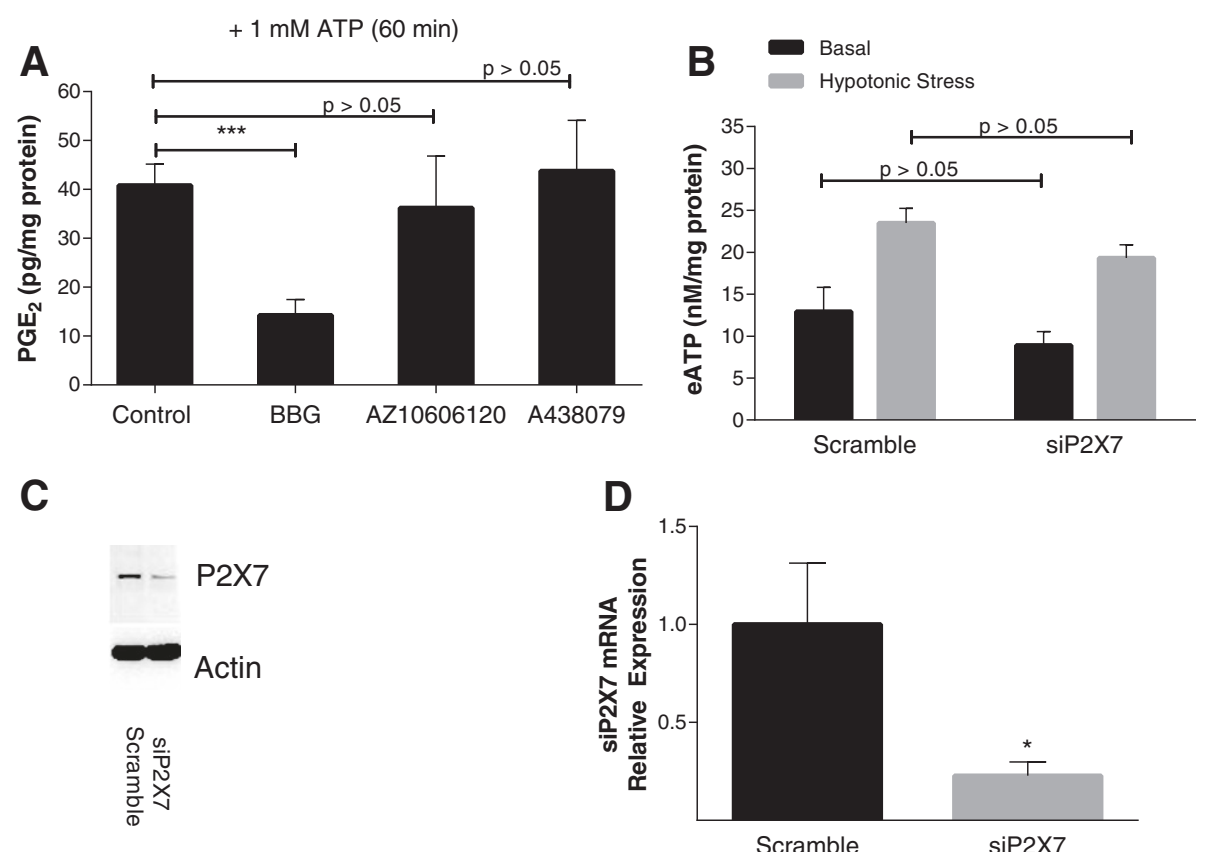

Figure 4 Role of P2X7 receptors in signaling and eATP efflux by chondrocytes. (A) Chondrocytes were treated with no additives (control) or P2X7 inhibitors (Brilliant Blue G (BBG), AZ10606120 or A438079) for $1 \mathrm{~h}$ in the presence of $1 \mathrm{mM}$ ATP. Prostaglandin $E_{2}\left(P_{G} E_{2}\right)$ levels in the media were measured using the Parameter ${ }^{T M}$ Prostaglandin $E_{2}$ kit (R\&D Systems). Bars represent mean \pm standard error. BBG reduced ATP-induced $P_{G E}$ levels $\left(n=8 ;{ }^{* * *} P<0.001\right)$. (B) Chondrocytes were transfected with siRNA for P2X7 or a scrambled control. After 48 h, cells were exposed to hypotonic media for 10 minutes (gray bars) or isotonic media (black bars) and eATP levels were measured. Bars represent mean \pm standard error. Under control conditions, a hypotonic challenge consistently increases (eATP). No differences in eATP levels were noted in siP2X7-treated chondrocyte media $(n=8 ; P>0.05)$. In parallel cultures at $48 \mathrm{~h}$, protein and mRNA were isolated from scramble or siRNA-treated cells as described and used to assess levels of P2X7 receptor protein (C) and mRNA (D). mRNA levels of P2X7 were suppressed in siRNA-treated cells $\left({ }^{*} P<0.05\right)$. Western blots compare the effects of siRNA effects on P2X7 receptor levels versus actin. 

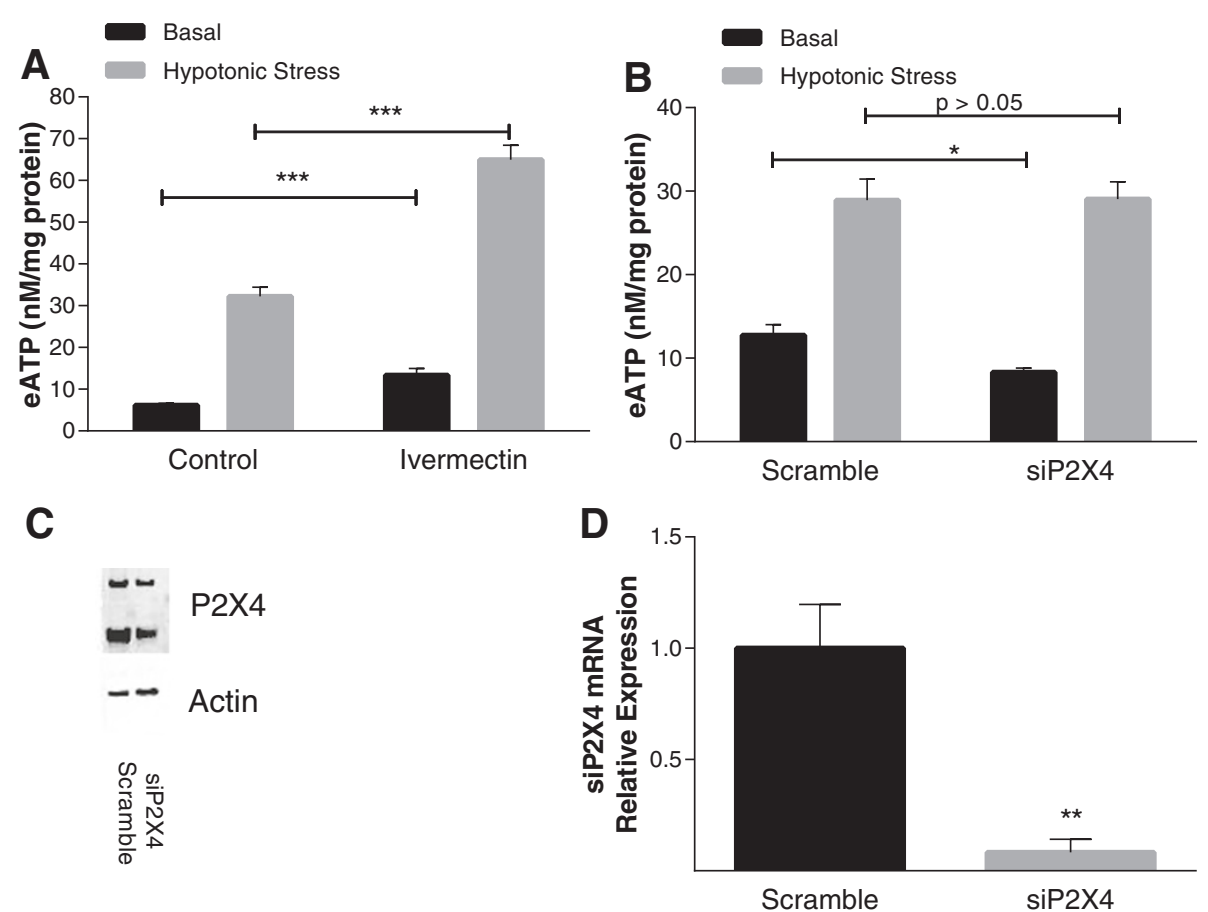

Figure 5 Role of P2X4 receptors in signaling and eATP release by chondrocytes. (A) Chondrocytes were treated with no additives (control) or $10 \mu \mathrm{M}$ ivermectin in $100 \mu \mathrm{l}$ of media for 30 minutes: $35 \mu \mathrm{l}$ of media were removed and replaced with $35 \mu \mathrm{l}$ of media (black bars) or $35 \mu \mathrm{l}$ of $\mathrm{H}_{2} \mathrm{O}$ (gray bars). eATP levels were measured after 10 minutes. Bars represent mean \pm standard error. Under control conditions, a hypotonic challenge consistently increases (eATP). Ivermectin increased eATP levels after a hypotonic challenge $\left(n=8:{ }^{* * *} P<0.001\right)$. (B) Chondrocytes were transfected with siRNA for P2X4 or a scrambled control. After 48 h, cells were exposed to hypotonic media for 10 minutes (gray bars) or isotonic media (black bars) and eATP levels were measured. Bars represent mean \pm standard error. eATP levels in P2X4 -silenced chondrocyte media were similar to those in the scramble control media $(n=8 ; P>0.05)$. In parallel cultures at $48 \mathrm{~h}$, protein and mRNA were isolated from scramble or siRNA-treated cells as described and used to assess levels of P2X4 receptor protein (C) and mRNA (D). siRNA for P2X4 decreased P2X4 mRNA $\left({ }^{* *} P<0.01\right)$. Western blots compare effects on $\mathrm{P} 2 \mathrm{X} 4$ receptor versus actin.

identifying participants and modulators of ATP efflux may provide insights regarding novel therapies for these diseases.

As is observed in most cell types, chondrocytes release a burst of ATP after exposure to hypotonic media. In chondrocytes, this effect is calcium dependent and is mimicked by a specific chemical agonist of TRPV4, as is true in other cell types [34,40]. While further work will be necessary to conclusively implicate TRPV4 in chondrocyte eATP release, TRPV4 levels are altered in OA chondrocytes, and dysregulation of ATP/PPi efflux could contribute to the excess calcification seen in $\mathrm{OA}$ and in TRPV4-deficient mice [22].

The potent effects of ANK silencing in reducing eATP levels confirm and mechanistically extend the important roles of this protein in cartilage homeostasis and disease. ANK levels are increased in OA [41] and CPP crystalcontaining cartilage [42], and expression of ANK has been implicated in maintaining the phenotype of healthy chondrocytes [43]. ANK levels are increased with mechanical stimuli in vertebral endplate chondrocytes [44]. We show here that altering levels of ANK is an effective way of manipulating eATP levels in chondrocyte cultures.

Our studies suggest that ANK directly affects eATP efflux. Suppressing ANK protein levels did not result in changes in ATP metabolizing ecto-enzymes. Moreover, the effect of ANK silencing on eATP levels was not mediated by changes in ePPi. As alkaline phosphatase is a marker of the hypertrophic phenotype and levels of alkaline phosphatase activity were unchanged in ANK-silenced cells, we have no evidence to suggest that an altered chondrocyte phenotype is responsible for the changes in eATP levels with ANK manipulation.

The drug, probenecid, acts as a potent inhibitor of both basal and stimulated ATP efflux in chondrocytes. Probenecid may be directly interacting with ANK, as has been hypothesized by Ho et al. [9], but may also inhibit hemichannels. We feel that this is an unlikely mechanism for the probenecid effect as no other hemichannel inhibitor reduced eATP efflux. Probenecid also functions as a weak phosphodiesterase inhibitor, but does not appear to act through this mechanism in chondrocytes [35]. The actions of organic anion transporters (OATs) 
may also be blocked by probenecid. However, the observations that OATs are downregulated by protein kinase $\mathrm{C}$ (PKc) [45], and that PKc activation increases chondrocyte eATP levels [8], argue against a likely role for OATs in eATP release. Although plasma levels of probenecid under therapeutic conditions are 10-fold lower than levels typically used in cell culture [46], this drug has a long history of safety and efficacy in patients with gout.

While ANK itself may transport ATP, our findings suggest that P2X7/4 receptors also contribute to eATP release by chondrocytes. Whether these receptors contain a large pore capable of transporting ATP or regulate such a pore is not clear. Our data suggest that, in chondrocytes, a P2X7/4-dependent pore releases $\mathrm{PGE}_{2}$ as well as ATP. The lack of effectiveness of the more specific P2X7 inhibitors supports a role for P2X4 in this process, which is further demonstrated by the effect of ivermectin, a relatively specific stimulant of $\mathrm{P} 2 \mathrm{X} 4$ receptormediated actions. Because reducing levels of P2X4 or P2X7 alone had no effect on eATP efflux, we hypothesize that either P2X4 and/or P2X7 can participate in eATP transport. The redundancy of this system may attest to the importance of eATP efflux in cartilage.

In some cell types, pannexin-1 hemichannels may be activated in response to $\mathrm{P} 2 \mathrm{X} 7$ receptor stimulation, and these serve as the conduit for ATP release. However, the ability of P2X7 receptors to facilitate non-selective pore formation is similar in macrophages from wild-type or pannexin-1 knockout mice [47]. In other cell types in which P2X7 receptors participate in eATP release, hemichannel inhibitors behave anomalously [16], and this may be the case in chondrocytes. Our findings differ from those of Garcia and Knight who showed that flufenamic acid reduced eATP release in bovine chondrocytes [12]. Variations in mechanisms among different species, effects of culture conditions and differences in ages of the animals may explain these differences. In a mouse growth-plate chondrocytic cell line, Iwamoto et al. showed an important role for pannexin-3 in eATP efflux [48]. Certainly, growth-plate chondrocytes differ from primary articular chondrocytes in many ways. Despite the use of a number of hemichannel inhibitors in a wide range of concentrations, however, we could not demonstrate a clear role for pannexins or connexins in our system.

These studies are not without limitations. Culture models may not fully reproduce the environment that chondrocytes see in situ. However, our cells retain all the phenotypic features of highly differentiated chondrocytes [49], and we showed similar behavior in regards to eATP efflux in chondrocytes embedded in an agarose construct. While membrane injury resulting from cell swelling may result in non-specific leakage of cell contents including ATP from the cell, the lack of evidence of toxicity and the specificity of the inhibitor effects makes this highly unlikely. The natural environment of healthy articular chondrocytes is hyperosmolar, and time may be necessary for chondrocytes to adjust to the lower osmolar milieu of culture media [27]. While we allowed cells to acclimatize for 24 hours before these experiments were undertaken, differences in absolute or relative osmolarity may exist between tissue culture models and conditions in vivo. We used a brief osmotic stress to elicit eATP efflux and further work will be necessary to explore the long-term effects of various osmotic states on eATP efflux. Last, we were unable to conclusively prove a role for P2X7/4 receptors using silencer technology. Ultimately, studies with mice deficient in one of more of these proteins may be necessary to demonstrate a role for these proteins in chondrocyte ATP efflux. We attempted to minimize concerns about off-target effects of pharmacologic inhibitors by carefully examining toxicity of these agents, as well as testing their actions on other factors impacting eATP levels.

\section{Conclusion}

In summary, we show here that ANK has a central role in eATP release by mature articular chondrocytes, and $\mathrm{P} 2 \mathrm{X} 7 / 4$ receptors may also participate in this process. As eATP has numerous catabolic effects in cartilage and contributes to calcium crystal arthritis, further progress in understanding mechanisms and identifying modulators of ATP release may result in additional therapies for common degenerative diseases of cartilage.

\section{Abbreviations}

5'NT: 5' nucleotidase; ANK: Progressive ankylosis gene product; BAPTA-AM: Bis-N,N,N',N'-tetraacetic acid-AM; BBG: Brilliant Blue G; BCP: Basic calcium phosphate; CPP: Calcium pyrophosphate; DMEM: Dulbecco's modified eagle's medium; eATP: extracellular adenosine triphosphate; ENPP1: Ecto-nucleoside triphosphohydrolase 1; ePPi: Extracellular pyrophosphate; HBSS: Hank's balanced salt solution; MTT: 3-(4,5-dimethylthiazol-2-yl)-2,5-diphenyltetrazolium bromide; $\mathrm{NaOH}$ : Sodium hydroxide: NaPPi: Sodium pyrophosphate; NTPPPH: Nucleoside triphosphate pyrophosphohydrolase; OA: Osteoarthritis; OAT: Organic anion transporter; $\mathrm{PGE}_{2}$ : Prostaglandin $\mathrm{E}_{2}$; PKc: Protein kinase $\mathrm{C}_{\text {; PNPMP: P-nitrophenol }}$ thymidine monophosphate; PNPP: P-nitrophenol phosphate; RT-PCR: Reverse transcription polymerase chain reaction; siRNA: Small interfering RNA; TBS: Tris-buffered saline; TRPV4: Transient receptor potential vanilloid 4; VSOAC: Volume-sensitive organic osmolyte and anion channels; VSOR: Volume-sensitive outwardly rectifying channels.

\section{Competing interests}

The authors declare they have no competing interests.

\section{Authors' contributions}

AKR designed the studies and drafted the manuscript. CMG performed all of the tissue culture experiments, western blotting and the biochemical assays included in this manuscript, assisted with manuscript preparation and drafted the figures. EMF performed all of the RT-PCR procedures including the experiments with siRNA. She also assisted in manuscript preparation, statistical analysis and figure design. MKL carried out the experiments with P2X7 inhibitors and measured PGE levels. GRD participated in study design and manuscript preparation. LMR assisted with study concept and design and helped to draft the manuscript. All authors read and approved the final manuscript. 


\section{Acknowledgements}

We would like to thank Johnsonville Foods, Inc., Watertown, WI for their generous donation of porcine tissue, Charlene J Williams, PhD, for her sage scientific advice, and the VA Research Service at the Zablocki VA Medical Center for space and support.

\section{Author details}

${ }^{1}$ Rheumatology Section, cc-111 W, Zablocki VA Medical Center, 5000 W. National Ave, Milwaukee, WI 53295-1000, USA. ${ }^{2}$ Rheumatology Division, Department of Medicine, Medical College of Wisconsin, Milwaukee, WI, USA. ${ }^{3}$ Department of Physiology and Biophysics, Case Western Reserve University, Cleveland, OH, USA.

Received: 28 March 2013 Accepted: 2 October 2013

Published: 17 October 2013

\section{References}

1. Dubyak GR: ATP release mechanisms. In Nucleotides in the regulation of bone formation and resorption. Edited by Burnstock G, Arnett T. London: CRC Press; 2006:100-141.

2. Millward-Sadler SJ, Wright MO, Flatman PW, Salter DM: ATP in the mechanotransduction pathway of normal human chondrocytes. Biorheology 2004, 41:567-575.

3. Ryan LM, Kurup IV, Derfus BA, Kushnaryov VM: ATP-induced chondrocalcinosis. Arthritis Rheum 1992, 35:1520-1524.

4. Leong WS, Russell RG, Caswell AM: Stimulation of cartilage resorption by extracellular ATP acting at P2-purinoceptors. Biochim Biophys Acta 1994, 1201:298-304

5. Hamilton SG, MCMahon SB: ATP as a peripheral mediator of pain. J Autonomic Nervous System 2000, 81:187-194.

6. Jin C, Frayssinet P, Pelker R, Cwirka D, Hu B, Vignery A, Eisenbarth SC, Flavell RA: NLRP3 inflammasome plays a critical role in the pathogenesis of hydroxyapatite-associated arthropathy. PNAS USA 2011, 108:14867-14872.

7. Scanzello CR, Plass A, Crow MK: Innate immune system activation in osteoarthritis: is osteoarthritis a chronic wound? Curr Opin Rheumatol 2008, 20:565-572.

8. Costello JC, Rosenthal AK, Kurup IV, Masuda I, Medhora M, Ryan LM: Parallel regulation of extracellular ATP and inorganic pyrophosphate: Roles of growth factors, transduction modulators and ANK. Conn Tissue Res 2011, 52:139-146

9. Ho AM, Johnson MD, Kingsley DM: Role of the mouse ank gene in tissue calcification and arthritis. Science 2000, 289:265-270.

10. Gurley KA, Reimer RJ, Kingsley DM: Biochemical and genetic analysis of ANK in arthritis and bone disease. Am J Human Genetics 2006 79:1017-1029

11. Lm R, Wortmann RL, Karas B, McCarty DJ Jr: Cartilage nucleoside triphosphate pyrophosphohydrolase. II. Role in extracellular pyrophosphate generation and nucleotide metabolism. Arthritis Rheum 1985, 28:413-418.

12. Garcia M, Knight MM: Cyclic loading opens hemichannels to release ATP as part of a chondrocyte mechanotransduction pathway. J Orth Res 2010, 28:510-515.

13. Sawada K, Echigo N, Juge N, Miyaji T, Otsuka M, Omote H, Yamamoto A, Moriyama Y: Identification of a vesicular nucleotide transporter. PNAS, USA 2008, 105:5683-5686

14. Orriss IR, Knight GE, Utting JC, Taylor SE, Burnstock G, Arnett TR: Hypoxia stimulates vesicular ATP release from rat osteoblasts. J Cell Physiol 2009, 220:155-162.

15. Sabirov RA, Okada Y: The maxi-anion channel: a classical channel playing novel roles through an unidentified molecular entity. J Physio/ Sci 2009, 59:3-21.

16. Ma W, Hui H, Pelegrin P, Suprenant A: Pharmacological characterization of pannexin-1 currents expressed in mammalian cells. J Pharmacol Exp Ther 2008, 328:409-418

17. Suadicani SO, Brosnan CF, Scemes E: P2X7 receptors mediate ATP release and amplification of astrocytic intercellular $\mathrm{Ca} 2+$ signaling. J Neurosci 2006, 26:1378-1385.

18. Skaper SD, Debetto P, Giusti P: The P2X7 purinergic receptor: from physiology to neurologic disorders. FASEB J 2010, 24:337-345.

19. Sorege RE, Trang T, Dorman R, Smith SB, Beggs S, Ritchie J, Austin JS, Zaykin DV, Vander Meulen H, Costigan M, Herbert TA, Yarkoni-Abitbul M, Tichauer
D, Livneh J, Gershon E, Zheng M, Tan K, John SL, Slade GD, Jordan J, Woolf CJ, Peltz G, Maixner W, Diatchenko L, Seltzer Z, Salter MW, Mogil JS: Genetically determined P2X7 receptor pore formation regulates variability in chronic pain sensitivity. Nature Med 2012, 18:595-599.

20. Boumechache M, Masin M, Edwardson JM, Górecki DC, Murrell-Lagnado R: Analysis of assembly and trafficking of native $\mathrm{P} 2 \mathrm{X} 4$ and $\mathrm{P} 2 \mathrm{X} 7$ receptor complexes in rodent immune cells. J Biol Chem 2009, 284:13446-13454.

21. Chao GH, West AC, Hung CT: Chondrocyte intracellular calcium, cytoskeletal organization, and gene expression responses to dynamic osmotic loading. Am J Physiol Cell Physiol 2006, 291:C718-C725.

22. Clark AL, Votta BJ, Kumar S, Leidtke W, Guilak F: Chondroprotective role of the osmotically sensitive ion channel transient receptor potential vanilloid 4. Arthritis Rheum 2010, 62:2973-2983.

23. Graff RD, Lazarowksi ER, Banes A, Lee GM: ATP release by mechanically loaded porcine chondrons in pellet culture. Arthritis Rheum 2000, 43:1571-1579.

24. Woehrle T, Yip L, Manohar M, Sumi Y, Yao Y, Chen Y, Junger WC: Hypertonic stress regulates $T$ cell function via pannexin-1 hemichannels and P2X receptors. J Leukoc Biol 2010, 88:1181-1188.

25. Korhonen RK, Han SK, Herzog W: Osmotic loading of in situ chondrocytes in their native environment. Mol Cell Biomechan 2010, 7:125-134.

26. Maroudas A: Balance between swelling pressure and collagen tension in normal and degenerate cartilage. Nature 1976, 260:808-809.

27. Urban JP, Hall AC, Gehl KA: Regulation of matrix synthesis rates by the ionic and osmotic environment of articular chondrocytes. J Cell Physiol 1993, 154:262-270.

28. Rosenthal AK, Cheung HS, Ryan LM: Transforming growth factor beta 1 stimulates inorganic pyrophosphate elaboration by porcine cartilage. Arthritis Rheum 1991, 34:904-911.

29. Seminario-Vidal L, Okada SF, Sesma Jl, Kreda SM, van Heusden CA, Zhu Y, Jones LC, O'Neal WK, Penuela S, Laird DW, Boucher RC, Lazarowski ER: Rho signaling regulates pannexin 1-mediated ATP release from airway epithelia. J Biol Chem 2011, 286:26277-26286.

30. Li A, Leung CT, Peterson-Yantorno K, Mitchell CH, Civan MM: Pathways for ATP release by bovine ciliary epithelial cells, the initial stop in purinergic regulation of aqueous humor inflow. Am J Physiol Cell Physiol 2010, 299:C1308-C1317.

31. Arkesteijn $\mathrm{CL}$ : A kinetic method for serum 5' -nucleotidase using stabilized glutamate dehydrogenase. J Clin Chem Clin Biochem 1976, 14:155-159.

32. Joseph SM, Buchakjian MR, Dubyak GR: Colocalization of ATP release sites and ecto-ATPase activity at the extracellular surface of human astrocytes. J Biol Chem 2003, 278:23331-23342.

33. Blum $A E$, Walsh $B C$, Dubyak GR: Extracellular osmolarity modulates $G$ protein-coupled receptor-dependent ATP release from 1321N1 astrocytoma cells. Am J Physiol Cell Physiol 2010, 298:C386-C396.

34. Shahidullah M, Mandal A, Delamere NA: TRPV4 in porcine lens epithelium regulates hemichannel-mediated ATP release and Na-K-ATPase activity. Am J Physiol Cell Physiol 2012, 302:C1751-C1761.

35. Rosenthal AK, Ryan LM: Probenecid inhibits transforming growth factor $\beta 1$ induced pyrophosphate elaboration by chondrocytes. J Rheumatol 1993, 21:896-900.

36. Pelegrin $P$, Surprenant A: Pannexin-1 mediates large pore formation and interleukin-1 $\beta$ release by the ATP-gated P2X7 receptor. EMBO J 2006, 25:825071

37. Bernier LP, Ase AR, Boué-Grabot E, Séguéla P: P2X4 receptor channels form large noncytolytic pores in resting and activated microglia. Glia 2012, 60:728-737.

38. Guo C, Masin M, Qureshi OS, Murrell-Lagnado RD: Evidence for functional P2X4/P2X7 heteromeric receptors. Mol Pharmacol 2007, 72:1447-1456.

39. Berenbaum F, Humbert L, Bereziat G, Thirion S: Concomittant recruitment of ERK $1 / 2$ and p38 MAPK signalling pathway is required for activation of cytoplasmic phospholipase A2 via ATP in articular chondrocytes. J Biol Chem 2003, 278:13680-13687.

40. Mihara H, Boudaka A, Sugiyama A, Moriyama Y, Tominaga M: Transient receptor potential vallinoid 4 (TRPV4)-dependent calcium influx and ATP release in mouse oesophageal keratinocytes. J Physiol 2011, 589:3471-3482.

41. Johnson K, Terkeltaub R: Upregulated ank expression in osteoarthritis can promote both chondrocyte MMP-13 expression and calcification via chondrocyte extracellular PPi excess. Osteoarthritis Cart 2004, 12:321-335.

42. Hirose J, Ryan LM, Masuda I: Up-regulated expression of cartilage intermediate-layer protein and ANK in patients with calcium 
pyrophosphate dihydrate crystal deposition disease. Arthritis Rheum 2002, 46:3218-3229.

43. Cailotto F, Sebillaud S, Netter P, Jouzeau JY, Bianchi A: The inorganic pyrophosphate transporter ANK preserves the differentiated phenotype of articular chondrocyte. J Biol Chem 2010, 285:10572-10582.

44. Xu HG, Hu CJ, Wang H, Liu P, Yang XM, Zhang Y, Want LT: Effects of mechanical strain on ANK, ENPP1 and TGF-B1 expression in rat endplate chondrocytes in vitro. Mol Med Reports 2011, 4:831-835.

45. VanWert AL, Gionfriddo MR, Sweet DH: Organic Anion Transporters: Discovery, Pharmacology, Regulation and Roles in Pathophysiology. Biopharm Drug Dispos 2010, 31:1-71.

46. Cunningham RF, Israili ZH, Dayton PG: Clinical pharmacokinetics of probenecid. Clin Pharmokinetics 1981, 6:135-151.

47. Qu Y, Misaghi S, Newton K, Gilmour LL, Louie S, Cupp JE, Dubyak GR, Hackos D, Dixit VM: Pannexin-1 is required for ATP release during apoptosis but not for inflammasome activation. J Immunol 2011, 186:6553-6561.

48. Iwamoto T, Nakmura T, Doyle A, Ishikawa M, DeVega S, Fukumoto S, Yamada Y: Pannexin 3 regulates intracellular ATP/CAMP levels and promotes chondrocyte differentiation. J Biol Chem 2010, 285:18948-18958.

49. Mitchell PG, Struve JA, McCarthy GM, Cheung HS: Basic calcium phosphate crystals stimulate cell proliferation and collagenase message accumulation in cultured adult articular chondrocytes. Arthritis Rheum 1992, 35:343-350

doi:10.1186/ar4337

Cite this article as: Rosenthal et al: The progressive ankylosis gene product ANK regulates extracellular ATP levels in primary articular chondrocytes. Arthritis Research \& Therapy 2013 15:R154.

\section{Submit your next manuscript to BioMed Central and take full advantage of:}

- Convenient online submission

- Thorough peer review

- No space constraints or color figure charges

- Immediate publication on acceptance

- Inclusion in PubMed, CAS, Scopus and Google Scholar

- Research which is freely available for redistribution 